\title{
Mathematical Modeling for Risk Averse Firm Facing Loss Averse Customer's Stochastic Uncertainty
}

\author{
Seungbeom Kim, Jinpyo Lee, and Minjae Park \\ College of Business Administration, Hongik University, Seoul, Republic of Korea \\ Correspondence should be addressed to Jinpyo Lee; jinpyo.lee@hongik.ac.kr
}

Received 24 January 2017; Revised 18 March 2017; Accepted 26 March 2017; Published 11 April 2017

Academic Editor: Huanqing Wang

Copyright (C) 2017 Seungbeom Kim et al. This is an open access article distributed under the Creative Commons Attribution License, which permits unrestricted use, distribution, and reproduction in any medium, provided the original work is properly cited.

To optimize the firm's profit during a finite planning horizon, a dynamic programming model is used to make joint pricing and inventory replenishment decision assuming that customers are loss averse and the firm is risk averse. We model the loss averse customer's demand using the multinomial choice model. In this choice model, we consider the acquisition and transition utilities widely used by a mental accounting theory which also incorporate the reference price and actual price. Then, we show that there is an optimal inventory policy which is base-stock policy depending on the accumulated wealth in each period.

\section{Introduction}

Joint control of inventory and price has long been widely used for many firms such as Amazon, Dell, and J. C. Penny [1]. However, as mentioned in [2], traditional inventory control models are mainly concerned with the properties of replenishment policies to optimize the expected total profit or cost during a planning horizon. We can say that the traditional models are good strategies for the risk neutral inventory decision maker who is insensitive to profit or cost variations. However, not all inventory decision makers are risk neutral but frequently risk averse, in which the risk averse inventory decision maker would prefer a certainty equivalent to taking the bet and possibly receiving nothing, where the certainty equivalent is defined as the amount that the decision maker would accept instead of the bet.

For a better operational decision and a successful marketing campaign, a firm's inventory decision makers should consider customer's behavior corresponding to the price set by the firm, carefully. Customer's behavior significantly influences firm's revenue so that also the firm's pricing and replenishment decisions are deeply influenced. The firm's decision makers should construct a good operational and marketing strategy. When you see repeat-purchase markets, consumers have expectation for the price, which is known as reference prices in prospect theory. Customers perceive fluctuating prices as discounts or overcharges relative to the reference prices formed by the previous prices. Moreover, this perception affects demand and thus firm's profit. For example, while a price discount might have a positive impact on sales on the short-run, the discounted price might result in the installation of a low price in consumers memory, eroding price expectations and willingness to pay and thereby negatively affecting profitability on the long run. It is important for a firm to understand (1) how consumers expectations for price and decisions for purchasing are affected by its pricing policy and history and (2) how prices should be set over time to optimize its utility. So, a firm needs to incorporate the behavior of loss averse customers into its strategy, to whom losses loom larger than gains. Since loss averse customers, to whom the disutility of a loss is greater than the utility of an equivalent gain, prudently consider the tradeoff between the perceived reference price from the previous prices and the current price when purchasing products, an unfavorable price is seen as a loss. So, it can significantly reduce customers' willingness to purchase and finally influence the reduction of retail sales.

So, in this paper, we consider a multiperiod inventory control model in which a risk averse firm faces loss averse customer's uncertain demand and makes an inventory replenishment and pricing decision by maximizing the firm's expected utility. 


\section{Literature Review}

We will go over the literature separately to compare with our research. First, the literature on the customer's behavior will be reviewed with respect to the loss aversion. Second, the literature on the firm's behavior will be reviewed with respect to the risk neutral utility. Then, finally, the literature on the firm's behavior will be reviewed with respect to the risk aversion.

There have been lots of research papers regarding the customers' irrational behavior since Barbara L. Fredrickson and Daniel Kahneman won the Nobel prize for their works on the prospect theory. Reference [3] shows that the decision makers are not rational and do not follow the expected utility theory and develop an alternative model, called prospect theory. In prospect theory, outcomes are valued as gains or losses relative to a current reference point instead of final levels of wealth and suggest that the utility of an equivalent gain is less than the disutility of a loss, which is referred to as loss aversion. Also, they present the concept of certainty effect which contributes to risk aversion over gains and to risk seeking over losses. Reference [4] mentions that consumer's choice is affected by the brands' position related to reference points with multiple attributes and that consumers keep their weight on losses from a reference point more than gains in the same amount, which is loss aversion. They develop a Multinomial Logit formulation which incorporates a reference-dependent choice model. Reference [10] addresses a behavioral decision bias in the newsvendor ordering problem: orders for low-profit products were higher than the expected profit-maximizing quantities, while orders for high-profit products were lower than the expected profit-maximizing quantities. They show that any of risk aversion, risk seeking preferences, prospect theory preferences, loss aversion, waste aversion, stockout aversion, or undervaluing opportunity costs cannot explain the bias pattern of ordering decision, but a preference of ex-post inventory error reduction and the anchoring heuristic might explain the bias pattern of ordering decision. Reference [11] proposes a behavioral theory to see the actual ordering decision in multilocation newsvendor problem. They assume that there are psychological costs for stockouts or leftovers and then show that decision makers psychological disutility for stockpots is less strong than that for leftovers. They test whether the pull-to-center bias exists in a multilocation newsvendor problem. Reference [14] proposes a dynamic pricing model based on the peak-end rule and reference price, where loss averse consumers make a purchasing decision depending on the lowest price and the most recent price. Here, as defined in [12], the peak-end rule is a psychological heuristic in which people's experience is evaluated largely based on how to feel at its peak (its lowest price point) and at its end (its most recent price), rather than based on the summation or average of every experience (past prices). Reference [13] shows that consumer's loss aversion behavior could result in higher prices and profits when consumer's valuation is higher enough than his/her search costs and the proportion of consumers with positive search costs is in an intermediate range. Also, they show that when forward-looking firms incorporate the negative effect of price promotions on future profits, the equilibrium range of price promotions may actually increase.

Second, we will see some traditional research papers on the risk neutral firm. Traditionally, many research literatures consider a model in which the firm is risk neutral and the customer is not loss averse. Actually, the demand from the customer is just affected by the list price set by the firm and is nonincreasing in the price. Reference [5] examines a newsvendor problem with risk neutral profit in which replenishment and selling price are decided simultaneously. References $[6,7,15,16]$ address the simultaneous decision problem of pricing and inventory replenishment in the face of demand uncertainty of which distributions depend on the price set by the risk neutral firm. References [8,9] address an inventory policy and a pricing strategy maximizing risk neutral expected profit given that the demand function is decreasing just in the price set by the firm.

Finally, we will see the literatures on the risk averse firm. The literature on the risk averse inventory control model is quite limited. Reference [17] considers a tradeoff between the stochastic profit's expected value and its standard deviation to hedge the undesirable uncertainty in stochastic profit, where a degree of risk aversion is reflected by the multiplication of some constant to the standard deviation. Reference [18] examines the effects of risk aversion in the newsboy problem in which comparative-static effects of changes in the various prices and costs are related to the newsboy's risk aversion. Reference [19] addresses an inventory model in which the objective is to optimize the expected exponential utility of the present value of net profits over time to incorporate the effects of sensitivity to risk. Reference [20] considers a newsvendor model in which a risk averse retailer faces uncertain demand and makes ordering quantity decisions and pricing decision with the objective of optimizing expected risk averse utility. In their model, the distribution of demand is a function of the price set by the risk averse retailer. Reference [2] incorporates risk aversion in multiperiod inventory models that coordinate inventory and pricing strategies.

The dynamic control model is utilized in a wide range of industries [21, 22] and its use is also prevalent in the control of inventory systems [23]. Reference [24] investigates the problem of adaptive tracking control for a class of switched stochastic nonlinear systems in nonstrict-feedback form with unknown nonsymmetric actuator dead-zone and arbitrary switching. Reference [19] formulates the dynamic programming models to solve multiperiod stochastic inventory problems with exponential utility function.

As reviewed above and summarized in Table 1, to the best of our knowledge, there is no research for a model combining the loss averse customer and risk averse firm simultaneously. So, it is pretty much new and will fill the research gap in the behavioral inventory control model.

\section{Assumptions}

In this paper, the following assumptions are used. 
TABLE 1: Comparison of our research with other existing researches.

\begin{tabular}{|c|c|c|c|c|c|}
\hline & {$[3,4]$} & [5-9] & {$[10,11]$} & {$[5,12,13]$} & Our research \\
\hline Risk averse & & & $\sqrt{ }$ & & $\sqrt{ }$ \\
\hline Loss averse & $\sqrt{ }$ & & & $\sqrt{ }$ & $\sqrt{ }$ \\
\hline Replenishment & & $\sqrt{ }$ & $\sqrt{ }$ & $\sqrt{ }$ & $\sqrt{ }$ \\
\hline Pricing & & $\sqrt{ }$ & $\sqrt{ }$ & $\sqrt{ }$ & $\sqrt{ }$ \\
\hline
\end{tabular}

Assumption 1. Unsatisfied demand is allowed to be backlogged. So, the inventory level at the beginning of each period can be negative.

Backlogging is widely used assumption in practice. If the demand is unsatisfied, lots of customers are willing to delay receiving what they want.

Assumption 2. Replenishment after ordering at the beginning of each period becomes available instantaneously.

In multiperiod inventory control problem, instantaneous replenishment is fairly good assumption if one period is set up widely enough for the replenishment to arrive in that period.

Assumption 3. A function $h_{t}(x)$ has the following properties.

(i) It is an inventory holding cost if $x$ is positive and shortage cost otherwise.

(ii) It is incurred at the end of each period and is convex.

(iii) $E\left[h_{t}(0)\right]=0$ is assumed in each period $t=1, \ldots, T$.

(iv) $\lim _{|x| \rightarrow \infty} h_{t}(x)=\infty$.

The leftover inventory at the end of each period incurs holding cost. Since shortages of inventory may result in the customer's cancelation of orders or losses in sale which lead to loss of goodwill or profit even for the firm's business itself, the unsatisfied demand at the end of each period also incurs some shortage cost. If there is not any leftover or shortage of inventory, there is no incurred cost. As the leftover or shortage of inventory increases, the incurred cost in each period should increase.

\section{Mathematical Formulation}

We consider a model in which there is a single firm selling single product to multiple customers. First, we will see how the loss averse customers behave given the price set by the firm. Then, we will analyze the risk averse firm's decision process by considering the loss averse customer's behavior.

4.1. Decision Model for Loss Averse Customer. All the customers are homogeneous, which implies that customer's decision is identically and independently distributed. The customer's demand is basically influenced by the selling price the firm offers to the customer in each period. Also, each customer's purchasing decision depends on the tradeoff between the selling price and a reference price. As mentioned in [13], it has been long recognized that consumer's purchasing decisions are influenced by reference prices and are disproportionately influenced more by perceived losses than perceived gains. For instance, consumers respond more strongly to selling price higher than their reference price than to selling price lower than their reference price. Here, a reference price is defined as an expected or "just" price for a product which a customer has in mind (see [25] for details). As in [14], we assume that the reference price $r_{t}$ at period $t$ is a convex combination of the actual price $p_{t-1}$ and the reference price $r_{t-1}$ at the previous period $t-1$. That is, for $t=2,3, \ldots, T$,

$$
r_{t}=\alpha r_{t-1}+(1-\alpha) p_{t-1}
$$

where $\alpha \in[0,1]$ is the weighting factor showing how much the current reference price is related to the past reference price and $r_{1}=p_{1}$. By [25], a customer's total utility by purchasing a product is the sum of acquisition utility $\left(v_{\text {acq }}\right)$ and transition utility $\left(v_{\text {trans }}\right)$. So, given a price $p_{t}$ and a reference price $r_{t}$ at period $t$, customer's total utility, $v\left(p_{t}, r_{t}\right)$, can be written as follows:

$$
v\left(p_{t}, r_{t}\right)=v_{\text {acq }}\left(p_{t}\right)+v_{\text {trans }}\left(p_{t}, r_{t}\right) .
$$

Here

$$
v_{\mathrm{acq}}\left(p_{t}\right)=a-b p_{t}+\gamma_{t}
$$

is an acquisition utility which depends on the value of the product purchased; in this case the actual price $p_{t}$ of product is also seen as the consumer surplus in standard economic models (see [25] for details). $\gamma_{t}$ is independently and identically Logit distributed with mean zero and variance $\pi^{2} / 3$ in each period (see [26] for details). And

$$
v_{\text {trans }}\left(p_{t}, r_{t}\right)=\left(r_{t}-p_{t}\right)^{+}-\lambda\left(r_{t}-p_{t}\right)^{-} \quad \text { for } \lambda \geq 1
$$

is a transition utility whose measure depends on the price $p_{t}$ the customer pays compared to the reference price $r_{t}$. Now, given the actual price $p_{t}$ and reference price $r_{t}$, a Multinomial Logit model is used for the customer's purchasing probability. For a given actual price $p_{t}$, a customer might purchase the product if the customer's total utility is greater than zero. The customer's purchasing probability at period $t$ is denoted as $P_{v, t}$. And $P_{v, t}$ at period $t$ can be written using Multinomial Logit model [27] as follows:

$$
P_{v, t}=P\left\{v\left(p_{t}, r_{t}\right) \geq 0\right\}=\frac{e^{a-b p_{t}+\left(r_{t}-p_{t}\right)^{+}+\lambda\left(r_{t}-p_{t}\right)^{-}}}{1+e^{a-b p_{t}+\left(r_{t}-p_{t}\right)^{+}+\lambda\left(r_{t}-p_{t}\right)^{-}}} .
$$

Since customers in the market are assumed to be homogeneous, the average demand for the given price $p_{t}$ at period $t$ is 
$M \times P_{v, t}$, where $M$ is the market size for the product's demand. Then, we can write the demand in period $t$ as follows:

$$
\begin{aligned}
D_{t}\left(p_{t}\right) & =M \times P_{v, t}+\epsilon_{t} \\
& =M \times \frac{e^{a-b p_{t}+\left(r_{t}-p_{t}\right)^{+}+\lambda\left(r_{t}-p_{t}\right)^{-}}}{1+e^{a-b p_{t}+\left(r_{t}-p_{t}\right)^{+}+\lambda\left(r_{t}-p_{t}\right)^{-}}}+\epsilon_{t},
\end{aligned}
$$

where $\epsilon_{t}$ is a random perturbation variable with mean zero. So, letting $d_{t} \equiv E\left[D_{t}\left(p_{t}\right)\right]$,

$$
d_{t}=M \times P_{v, t}=M \times \frac{e^{a-b p_{t}+\left(r_{t}-p_{t}\right)^{+}+\lambda\left(r_{\mathrm{t}}-p_{t}\right)^{-}}}{1+e^{a-b p_{t}+\left(r_{t}-p_{t}\right)^{+}+\lambda\left(r_{t}-p_{t}\right)^{-}}}
$$

is an expected demand in each period. Also, it is just a function of one decision variable $p_{t}$, which can be written as $f\left(p_{t}\right)$, since $r_{t}$ is the just combination of previous information which is known. Then, we can write $p_{t}$ as an inverse function of the expected demand $d_{t}$, which can be written as $f^{-1}\left(d_{t}\right)$.

So far, we see a mathematical expression for the loss averse customer's decision process. Now, we will see the mathematical expression for the risk averse firm's decision process.

4.2. Decision Model for Risk Averse Firm. For the risk averse firm's decision process, the risk is measured using the increasing and concave utility function and the first derivative of this concave function is decreasing. So, the marginal gain is less than the marginal loss with respective of the same amount of money. Also, as mentioned in [23, 28], to address the temporal risk problem caused by the expected utility model, a utility model over a stream of consumption can be a solution in which the firm's manager is permitted to lend or borrow to make the income flow smooth as the uncertainties over time.

Extending the consumption model in [2] to deal with loss averse customer, the firm's decision problem incorporates consumption, saving, and borrowing decisions as well as inventory replenishment $y$ and pricing decisions $p$ as follows. That is, given inventory level $x$ and an accumulated wealth $w$ at the beginning of period $t$, the firm should decide the order up to level $y$ and the selling price $p$ by optimizing the following problem:

$$
\bar{J}_{t}(x, w)=\max _{y \geq x, \underline{p}_{t} \leq p \leq \bar{p}_{t}} E\left[\bar{G}_{t}(x, w, y, p)\right],
$$

where

$$
\begin{aligned}
& \bar{G}_{t}(x, w, y, p)=\max _{w^{\prime}}\left\{u _ { t } \left(w-\frac{w^{\prime}}{1+r_{f}}-c_{t}(y-x)\right.\right. \\
& \left.+p D_{t}(p)-h_{t}\left(y-D_{t}(p)\right)\right)+\bar{J}_{t+1}(y \\
& \left.\left.-D_{t}(p), w^{\prime}\right)\right\},
\end{aligned}
$$

where $u_{t}(\cdot)$ is an increasing and concave utility function to capture the firm's risk aversion. $c_{t}$ is a variable cost to purchase or produce each product. The third, fourth, and fifth terms in the function $u_{t}(\cdot)$

$$
-c_{t}(y-x)+p D_{t}(p)-h_{t}\left(y-D_{t}(p)\right)
$$

are the net income earned during the period $t$. And by adding the accumulated wealth $w$ just before the period $t$ to these values,

$$
w-c_{t}(y-x)+p D_{t}(p)-h_{t}\left(y-D_{t}(p)\right)
$$

is the accumulated wealth up to period $t$. Now, by capturing the present value $w^{\prime} /\left(1+r_{f}\right)$ of the accumulated wealth $w^{\prime}$ in the next period

$$
w-\frac{w^{\prime}}{1+r_{f}}-c_{t}(y-x)+p D_{t}(p)-h_{t}\left(y-D_{t}(p)\right)
$$

is the firm's consumption during period $t$, where $w^{\prime} /\left(1+r_{f}\right)$ is saving if positive or borrowing otherwise. $r_{f}$ is the risk-free interest rate in the finance market. In the last period $T$, it is assumed that the firm should consume everything, which is $w^{\prime}=0$ at the period $T$, and thus for all $y$ and $p$

$$
\begin{aligned}
& \bar{G}_{T}(x, w, y, p) \\
& \quad=u_{T}\left(w-c_{T}(y-x)+p D_{T}(p)-h_{T}\left(y-D_{t}(p)\right)\right) .
\end{aligned}
$$

As mentioned above, $p_{t}=f^{-1}\left(d_{t}\right)$. So, we can write the above inventory firm's decision problem as follows:

$$
\bar{J}_{t}(x, w)=\max _{y \geq x, \underline{d}_{t} \leq d \leq \bar{d}_{t}} E\left[\bar{G}_{t}(x, w, y, d)\right],
$$

where

$$
\begin{gathered}
\bar{G}_{t}(x, w, y, d)=\max _{w^{\prime}}\left\{u _ { t } \left(w-\frac{w^{\prime}}{1+r_{f}}-c_{t}(y-x)\right.\right. \\
\left.\left.+p_{t}(d) d-h_{t}(y-d)\right)+\bar{J}_{t+1}\left(y-d, w^{\prime}\right)\right\} .
\end{gathered}
$$

For the convenience, we transform the problem using the parameter space shift and define $J_{t}(x, w)$ and $G_{t}(x, w, y, d)$ as follows:

$$
\begin{aligned}
& J_{t}(x, w) \equiv \bar{J}_{t}\left(x, w-c_{t} x\right) \\
& G_{t}(x, w, y, d) \equiv \max _{z}\left\{u _ { t } \left(w-\frac{z}{1+r_{f}}\right.\right. \\
& \quad+\left(\frac{c_{t+1}}{1+r_{f}}-c_{t}\right) y+\left(p_{t}(d)-\frac{c_{t+1}}{1+r_{f}}\right) d \\
& \left.\left.\quad-h_{t}(y-d)\right)+J_{t+1}(y-d, z)\right\}
\end{aligned}
$$

Then, we have the following lemma. 
Lemma 4. Equation (14) can be written as the following equivalent problem.

$$
J_{t}(x, w)=\max _{y \geq x, \underline{d}_{t} \leq d \leq \bar{d}_{t}} E\left[G_{t}(x, w, y, d)\right],
$$

where

$$
\begin{aligned}
& G_{t}(x, w, y, d)=\max _{z}\left\{u _ { t } \left(w-\frac{z}{1+r_{f}}\right.\right. \\
& \quad+\left(\frac{c_{t+1}}{1+r_{f}}-c_{t}\right) y+\left(p_{t}(d)-\frac{c_{t+1}}{1+r_{f}}\right) d \\
& \left.\left.\quad-h_{t}(y-d)\right)+J_{t+1}(y-d, z)\right\}
\end{aligned}
$$

where

$$
\begin{aligned}
G_{T} & (x, w, y, d) \\
& =u_{T}\left(w-c_{T} y+p_{T}(d) d-h_{T}(y-d)\right) .
\end{aligned}
$$

Proof. Given $x$ and $w$, it is sufficient to show that

$$
\begin{aligned}
& \max _{y \geq x, \underline{d}_{t} \leq d \leq \bar{d}_{t}} E\left[G_{t}(x, w, y, d)\right] \\
& =\max _{y \geq x, \underline{d}_{t} \leq d \leq \bar{d}_{t}} E\left[\bar{G}_{t}\left(x, w-c_{t} x, y, d\right)\right] .
\end{aligned}
$$

Equivalently, given $x, w, y$, and $d$, we only need to show that for all random realization

$$
G_{t}(x, w, y, d)=\bar{G}_{t}\left(x, w-c_{t} x, y, d\right) .
$$

Now, start with $\bar{G}_{t}\left(x, w-c_{t} x, y, p\right)$ as follows:

$$
\begin{aligned}
& \bar{G}_{t}\left(x, w-c_{t} x, y, p\right)=\max _{w^{\prime}}\left\{u _ { t } \left(w-c_{t} x-\frac{w^{\prime}}{1+r_{f}}\right.\right. \\
& \left.-c_{t}(y-x)+p D_{t}(p)-h_{t}\left(y-D_{t}(p)\right)\right) \\
& \left.+\bar{J}_{t+1}\left(y-D_{t}(p), w^{\prime}\right)\right\}=\max _{w^{\prime}}\left\{u_{t}(w\right. \\
& -\frac{w^{\prime}+c_{t+1}\left(y-D_{t}(p)\right)-c_{t+1}\left(y-D_{t}(p)\right)}{1+r_{f}}-c_{t} y \\
& \left.+p D_{t}(p)-h_{t}\left(y-D_{t}(p)\right)\right)+\bar{J}_{t+1}(y \\
& -D_{t}(p), w^{\prime}+c_{t+1}\left(y-D_{t}(p)\right) \\
& \left.\left.-c_{t+1}\left(y-D_{t}(p)\right)\right)\right\}=\max _{w^{\prime}}\left\{u_{t}(w\right. \\
& -\frac{w^{\prime}+c_{t+1}\left(y-D_{t}(p)\right)}{1+r_{f}}+\left(\frac{c_{t+1}}{1+r_{f}}-c_{t}\right) y
\end{aligned}
$$

$$
\begin{aligned}
& \left.+\left(p_{t}-\frac{c_{t+1}}{1+r_{f}}\right) D_{t}(p)-h_{t}\left(y-D_{t}(p)\right)\right) \\
& +\bar{J}_{t+1}\left(y-D_{t}(p), w^{\prime}+c_{t+1}\left(y-D_{t}(p)\right)\right. \\
& \left.\left.-c_{t+1}\left(y-D_{t}(p)\right)\right)\right\} .
\end{aligned}
$$

Now, let $w^{\prime}+c_{t+1}\left(y-D_{t}(p)\right)$ be replaced by $z$. Then, since maximizing over $z$ with given $y$ and $p$ does not change the optimality which is obtained by maximizing over $w^{\prime}$, we can equivalently write as follows; for all $x, w, y$ and $p$,

$$
\begin{aligned}
& \bar{G}_{t}\left(x, w-c_{t} x, y, p\right)=\max _{z}\left\{u _ { t } \left(w-\frac{z}{1+r_{f}}\right.\right. \\
& +\left(\frac{c_{t+1}}{1+r_{f}}-c_{t}\right) y+\left(p_{t}-\frac{c_{t+1}}{1+r_{f}}\right) D_{t}(p) \\
& \left.-h_{t}\left(y-D_{t}(p)\right)\right)+\bar{J}_{t+1}\left(y-D_{t}(p), z\right. \\
& \left.\left.-c_{t+1}\left(y-D_{t}(p)\right)\right)\right\}=\max _{z}\left\{u _ { t } \left(w-\frac{z}{1+r_{f}}\right.\right. \\
& +\left(\frac{c_{t+1}}{1+r_{f}} c_{t}\right) y+\left(p_{t}-\frac{c_{t+1}}{1+r_{f}}\right) D_{t}(p) \\
& \left.\left.-h_{t}\left(y-D_{t}(p)\right)\right)+J_{t+1}\left(y-D_{t}(p), z\right)\right\} \\
& =G_{t}(x, w, y, d) .
\end{aligned}
$$

Thus, we have

$$
\begin{aligned}
& \max _{y \geq x, \underline{d}_{t} \leq d \leq \bar{d}_{t}} E\left[G_{t}(x, w, y, d)\right] \\
& =\max _{y \geq x, \underline{d}_{t} \leq d \leq \bar{d}_{t}} E\left[\bar{G}_{t}\left(x, w-c_{t} x, y, d\right)\right]
\end{aligned}
$$

and the result holds.

4.3. Optimal Policy. In this section, we characterize the firm's optimal inventory control policy. First, we need to show that $E\left[G_{t}(x, w, y, d)\right]$ is jointly concave in $x, w, y$, and $d$.

Lemma 5. Suppose that the customer is loss averse such that the demand function is (6). Then, for each period $t$,

(1) $E\left[G_{t}(x, w, y, d)\right]$ is jointly concave in $x, w, y$, and $d$,

(2) $J_{t}(x, w)$ is jointly concave in $x$ and $w$.

Proof. $J_{T+1}(x, w)$ is jointly concave. So, using mathematical induction, suppose that $J_{t+1}(x, w)$ is jointly concave in $x$ and $w$. First, we have to verify that

$$
\left(\frac{c_{t+1}}{1+r_{f}}-c_{t}\right) y+\left(p_{t}(d)-\frac{c_{t+1}}{1+r_{f}}\right) d-h_{t}(y-d)
$$

is jointly concave in $y$ and $d$. The first term is linear in $y$. The third term is also jointly concave in $y$ and $d$ since $h_{t}(\cdot)$ 
is a convex function. Now, we need to verify that the second term is concave in $d$. It is sufficient to show that the second derivative of the second term with respect to $d$ is negative for any value of $r_{t}$; that is,

$$
\frac{d^{2}}{d d^{2}}\left[\left(p_{t}-\frac{c_{t+1}}{1+r_{f}}\right) d\right]<0 \quad \forall r_{t}
$$

Now, start with the expected demand $d$ which is

$$
d=M \times P_{v, t}=M \times \frac{e^{a-b p_{t}+\left(r_{t}-p_{t}\right)^{+}-\lambda\left(r_{t}-p_{t}\right)^{-}}}{1+e^{a-b p_{t}+\left(r_{t}-p_{t}\right)^{+}-\lambda\left(r_{t}-p_{t}\right)^{-}}}
$$

where $p_{t} \equiv p_{t}(d)$. Suppose that $r_{t}<p_{t}$. Then, the first derivative of both sides of (27) with respect to $d$ will be

$$
1=M \times \frac{e^{a-b p_{t}-\lambda\left(r_{t}-p_{t}\right)^{-}}(-b-\lambda)\left(d p_{t} / d d\right)\left(1+e^{a-b p_{t}-\lambda\left(r_{t}-p_{t}\right)^{-}}\right)-\left(e^{a-b p_{t}-\lambda\left(r_{t}-p_{t}\right)^{-}}\right)^{2}(-b-\lambda)\left(d p_{t} / d d\right)}{\left(1+e^{a-b p_{t}-\lambda\left(r_{t}-p_{t}\right)^{-}}\right)^{2}} .
$$

Thus,

$$
\begin{aligned}
& \frac{d p_{t}}{d d}=\frac{\left(1+e^{a-b p_{t}-\lambda\left(r_{t}-p_{t}\right)^{-}}\right)^{2}}{M \times e^{a-b p_{t}-\lambda\left(r_{t}-p_{t}\right)^{-}}(-b-\lambda)}, \\
& \frac{d^{2} p_{t}}{d d^{2}}=\frac{\left(e^{a-b p_{t}-\lambda\left(r_{t}-p_{t}\right)^{-}}-1\right)\left(1+e^{a-b p_{t}-\lambda\left(r_{t}-p_{t}\right)^{-}}\right)^{3}}{\left(M \times e^{a-b p_{t}-\lambda\left(r_{t}-p_{t}\right)^{-}}\right)^{2}(-b-\lambda)}, \\
& \frac{d^{2}}{d d^{2}}\left[\left(p_{t}-\frac{c_{t+1}}{1+r_{f}}\right) d\right] \\
& =\frac{d}{d d}\left[\frac{d p_{t}}{d d} d+\left(p_{t}-\frac{c_{t+1}}{1+r_{f}}\right)\right]=2 \frac{d p_{t}}{d d}+\frac{d^{2} p_{t}}{d d^{2}} d \\
& =\frac{2\left(1+e^{a-b p_{t}-\lambda\left(r_{t}-p_{t}\right)^{-}}\right)^{2}}{M \times e^{a-b p_{t}-\lambda\left(r_{t}-p_{t}\right)^{-}}(-b-\lambda)} \\
& +\frac{\left(e^{a-b p_{t}-\lambda\left(r_{t}-p_{t}\right)^{-}}-1\right)\left(1+e^{a-b p_{t}-\lambda\left(r_{t}-p_{t}\right)^{-}}\right)^{3}}{\left(M \times e^{a-b p_{t}-\lambda\left(r_{t}-p_{t}\right)^{-}}\right)^{2}(-b-\lambda)} \\
& \frac{M \times e^{a-b p_{t}-\lambda\left(r_{t}-p_{t}\right)^{-}}}{1+e^{a-b p_{t}-\lambda\left(r_{t}-p_{t}\right)^{-}}} \\
& =\frac{2\left(1+e^{a-b p_{t}-\lambda\left(r_{t}-p_{t}\right)^{-}}\right)^{2}}{M \times e^{a-b p_{t}-\lambda\left(r_{t}-p_{t}\right)^{-}}(-b-\lambda)} \\
& +\frac{\left(e^{a-b p_{t}-\lambda\left(r_{t}-p_{t}\right)^{-}}-1\right)\left(1+e^{a-b p_{t}-\lambda\left(r_{t}-p_{t}\right)^{-}}\right)^{2}}{M \times e^{a-b p_{t}-\lambda\left(r_{t}-p_{t}\right)^{-}}(-b-\lambda)}
\end{aligned}
$$

$$
=\frac{\left(e^{a-b p_{t}-\lambda\left(r_{t}-p_{t}\right)^{-}}+1\right)\left(1+e^{a-b p_{t}-\lambda\left(r_{t}-p_{t}\right)^{-}}\right)^{2}}{M \times e^{a-b p_{t}-\lambda\left(r_{t}-p_{t}\right)^{-}}(-b-\lambda)}
$$

which is strictly negative. Also, by the same procedure as in $r_{t} \leq p_{t}$, we can see that for $r_{t} \geq p_{t}$

$$
\frac{d^{2}}{d d^{2}}\left[\left(p_{t}-\frac{c_{t+1}}{1+r_{f}}\right) d\right]
$$

is strictly negative. Therefore, for any $r_{t},\left(p_{t}(d)-c_{t+1} /\left(1+r_{f}\right)\right) d$ is concave in $d$. Thus,

$$
\left(\frac{c_{t+1}}{1+r_{f}}-c_{t}\right) y+\left(p_{t}(d)-\frac{c_{t+1}}{1+r_{f}}\right) d-h_{t}(y-d)
$$

is jointly concave in $y$ and $d$, and also

$$
\begin{aligned}
& G_{t}(x, w, y, d)=\max _{z}\left\{u _ { t } \left(w-\frac{z}{1+r_{f}}\right.\right. \\
& \quad+\left(\frac{c_{t+1}}{1+r_{f}}-c_{t}\right) y+\left(p_{t}(d)-\frac{c_{t+1}}{1+r_{f}}\right) d \\
& \left.\left.\quad-h_{t}(y-d)\right)+V_{t+1}(y-d, z)\right\}
\end{aligned}
$$

is jointly concave in $x, w, y$, and $d$, which implies that $E\left[G_{t}(x, w, y, d)\right]$ is jointly concave in $x, w, y$, and $d$. Now, we need to show that $J_{t}(x, w)$ is jointly concave in $x$ and $w$. Suppose that, for any $x_{0}, w_{0}, x_{1}, w_{1}, \lambda \in(0,1)$; let $y_{0}$ and $y_{1}$ be such that $J_{t}\left(x_{0}, w_{0}\right)=\max _{\underline{d}_{t} \leq d \leq \bar{d}_{t}} E\left[G_{t}\left(x_{0}, w_{0}, y_{0}, d\right)\right]$ and $J_{t}\left(x_{1}, w_{1}\right)=\max _{\underline{d}_{t} \leq d \leq \bar{d}_{t}} E\left[G_{t}\left(x_{1}, w_{1}, y_{1}, d\right)\right]$. Then, we have

$$
\begin{aligned}
J_{t}\left((1-\lambda) x_{0}+\lambda x_{1},(1-\lambda) w_{0}+\lambda w_{1}\right) & =\max _{y \geq(1-\lambda) x_{0}+\lambda x_{1}}\left\{\max _{\underline{d}_{t} \leq d \leq \bar{d}_{t}} E\left[G_{t}\left((1-\lambda) x_{0}+\lambda x_{1},(1-\lambda) w_{0}+\lambda w_{1}, y, d\right)\right]\right\} \\
& \geq \max _{\underline{d}_{t} \leq d \leq \bar{d}_{t}} E\left[G_{t}\left((1-\lambda) x_{0}+\lambda x_{1},(1-\lambda) w_{0}+\lambda w_{1},(1-\lambda) y_{0}+\lambda y_{1}, d\right)\right]
\end{aligned}
$$




$$
\begin{aligned}
& \geq(1-\lambda) \max _{\underline{d}_{t} \leq d \leq \bar{d}_{t}} E\left[G_{t}\left(x_{0}, w_{0}, y_{0}, d\right)\right]+\lambda \max _{\underline{d}_{t} \leq d \leq \bar{d}_{t}} E\left[G_{t}\left(x_{1}, w_{1}, y_{1}, d\right)\right] \\
& =(1-\lambda) J_{t}\left(x_{0}, w_{0}\right)+\lambda J_{t}\left(x_{1}, w_{1}\right),
\end{aligned}
$$

where the first equality is from the definition of $J_{t}(x, w, y, d)$ and the second inequality is from maximum and the third inequality is from the joint concavity of $E\left[G_{t}(x, w, y, d)\right]$. Thus, $J_{t}(x, w)$ is jointly concave in $x$ and $w$.

Proposition 6. Suppose that the customer is loss averse such that the demand function is (6). For each period $t$, there exists an optimal base-stock inventory policy which depends on wealth at the beginning of period $t$.

Remark 7. We can verify the result of Proposition 6 easily as follows. Suppose that $y^{*}(w)$ is an optimal solution to the following problem:

$$
\max _{y \geq x}\left\{\max _{\underline{d}_{t} \leq d \leq \bar{d}_{t}} E\left[G_{t}(x, w, y, d)\right]\right\} .
$$

Since $E\left[G_{t}(x, w, y, d)\right]$ is jointly concave in $x, w, y$, and $d$ by Lemma 5, it is optimal to order up to $y^{*}(w)$ if $x<y^{*}(w)$ and not to order otherwise. This implies that there exists an optimal base-stock inventory policy which depends on wealth at the beginning of each period $t$.

\section{Numerical Example}

In this section, we provide a numerical example with time horizon 4 to show how our model actually works and how the expected utility objectives will change over the various risk averse factors and various loss averse factors.

To consider a firm's risk aversion, an exponential utility function, $u(x)=-e^{-x / R}$, has been used for our numerical example, where $R$ is the firm's risk averse factor. This exponential utility function is increasing and concave. Also, as $R$ decreases (increases), the firm's risk aversion increases (decreases). By (6), we used the following demand function:

$$
D_{t}\left(p_{t}\right)=\left[M \times \frac{e^{a-b p_{t}+\left(r_{t}-p_{t}\right)^{+}-\lambda\left(r_{t}-p_{t}\right)^{-}}}{1+e^{a-b p_{t}+\left(r_{t}-p_{t}\right)^{+}-\lambda\left(r_{t}-p_{t}\right)^{-}}}+\epsilon_{t}\right]^{+},
$$

where $[x]^{+}=\max [x, 0],[x]^{-}=\min [x, 0], M=40, a=$ 16 , and $b=1$. The customer's loss averse factor $\lambda$ is taken from the following values: $\{1,1.1,1.3,1.5,1.7,1.9,2,3,4\}$. The random variable, $\epsilon_{t}$, is uniformly distributed as follows.

$$
\begin{aligned}
P\left\{\epsilon_{1}=4\right\} & =P\left\{\epsilon_{2}=4\right\}=P\left\{\epsilon_{3}=-2\right\}=P\left\{\epsilon_{4}=-4\right\} \\
& =\frac{1}{4} .
\end{aligned}
$$

The other parameters in our model have the following values; unit purchasing cost is 2 , unit holding cost is 1 , unit shortage cost for lost sale is 4 , and salvage value is 1 .
Interestingly, for some numerical instances, the optimal base-stock increases as the firm's risk aversion increases. For this phenomenon, please see Figure 2(a) when the customer's loss aversion is 1.3 and Figure 2(b) when the customer's loss aversion is 1.7. In general, we cannot say that this is true. In some experiments, the optimal base-stock tends to be monotonically increasing (decreasing) in response to increasing (decreasing) risk aversion. However, even though such a monotonic property might be desirable, we have numerical examples that violate this property as the risk aversion level is changed. We have also observed that the changes of the optimal base-stock by changing the firm's risk aversion are not large.

Let $\Pi_{N}$ be the optimal expected utility for the loss-neutral customer and let $\Pi_{R}$ be the optimal expected utility for the loss averse customer. Then, using the following equation

$$
\frac{\Pi_{R}-\Pi_{N}}{\Pi_{N}}
$$

we can see the impact of the customer's loss aversion on the firm's optimal expected utility. Figure 1 shows that for various loss averse value $\{1.0,1.3,1.5,1.7,2.0,3.0\}$ and the risk aversion value at 100 , the loss aversion positively influences the firm's utility. When the customer is very loss averse (e.g., the loss aversion is 3.0), the firm's utility is expected to be reduced by approximately $38 \%$, if the firm does not take the customer's loss aversion into account.

\section{Conclusion}

In this paper, we analyze the multiperiod dynamic inventory control problem in which there are a risk averse firm selling single product and many loss averse customers. As mentioned in Introduction, there are lots of research papers considering only loss averse customer or considering only risk averse firm's strategy. In this paper, we consider dynamic mathematical modeling in which both loss averse customers and risk averse firm are incorporated. Loss averse customers are Multinomial Logit modeled using the acquisition utility and transition utility relative to the reference price. The reference price in each period is considered as a convex combination of the actual price and the reference price at the very previous period. To capture the firm's risk aversion, we incorporate the firm's consumption, saving, and borrowing decisions as well as inventory replenishment and pricing decisions. Then, we show that there exists an optimal basestock inventory policy depending on accumulated wealth in each period.

For the future research, the following can be considered:

(1) One could incorporate various systemic biases in modeling the decisions of the customers such as regret [14] and anchoring [11]. 


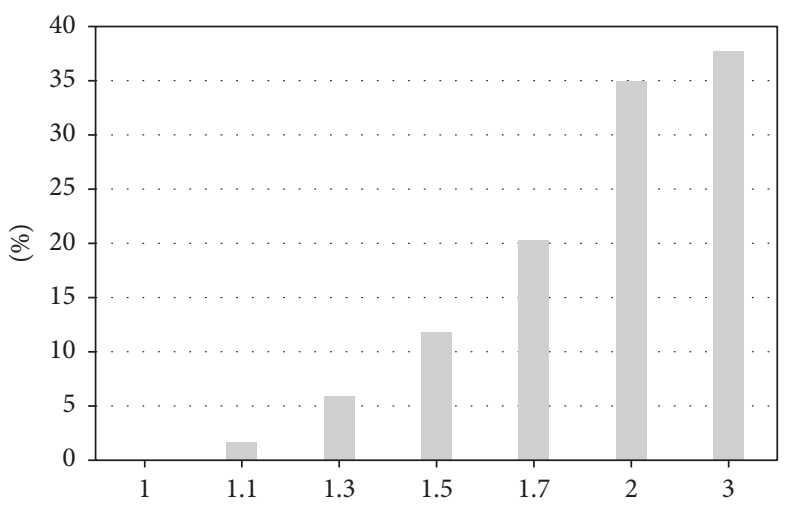

FiguRE 1: $\left(\Pi_{R}-\Pi_{N}\right) / \Pi_{N}$ for various customer's loss aversion $\{1.0,1.1,1.3,1.5,1.7,2.0,3.0\}$.

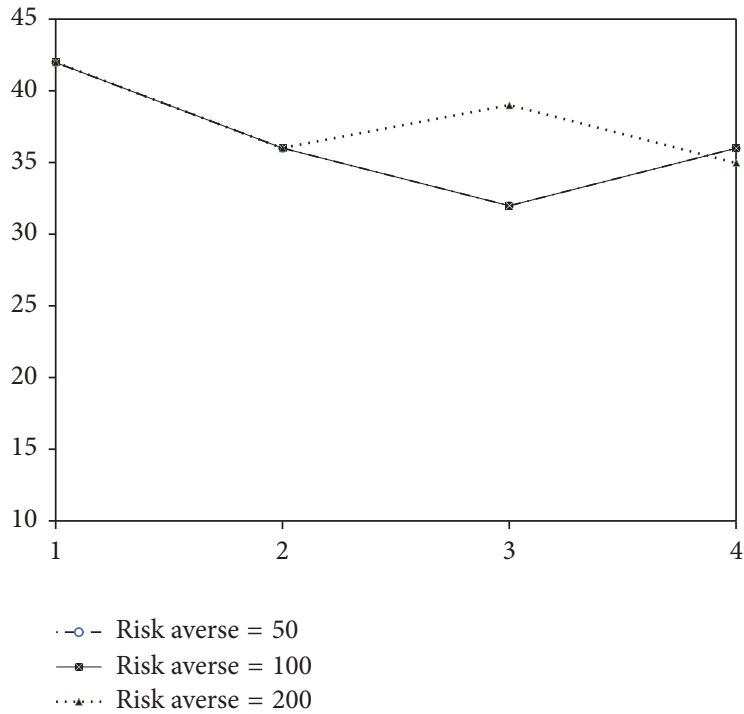

(a) When loss aversion is 1.3

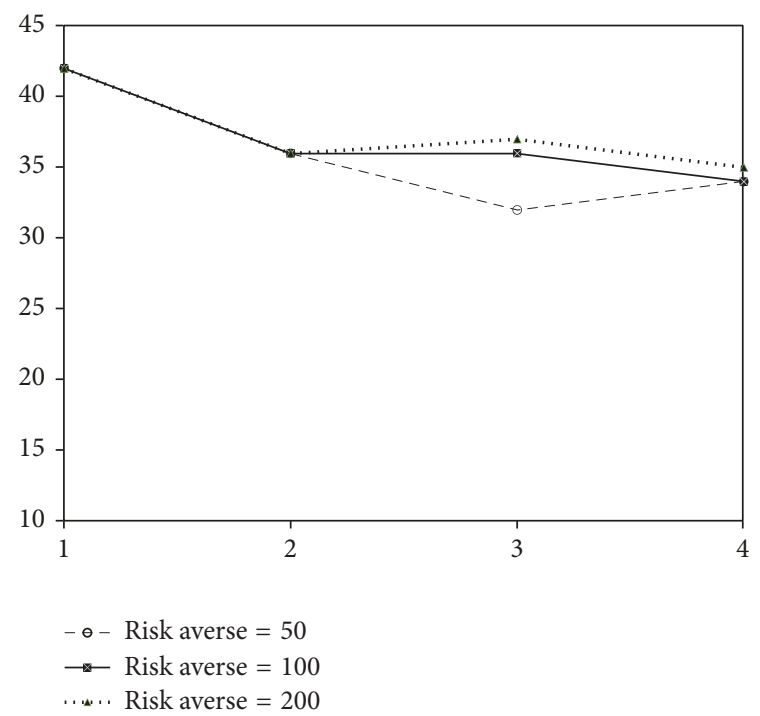

(b) When loss aversion is 1.7

FIGURE 2: Optimal base-stock for various firm’s risk aversion $\{50,100,200\}$.

(2) It would consider the case where the customers are strategic; for example, they make an intertemporal purchase decision $[29,30]$.

(3) In this research, we consider single market in which a firm plays. For the comprehensive view, market competition could be considered so that one can see the effect of heterogenous markets on the firm's decision and performance.

(4) One who might be interested in behavioral operations, marketing, and promotion strategy together with choice model could use our result as a foundation for one's future research.

\section{Conflicts of Interest}

The authors declare that there are no conflicts of interest regarding the publication of this paper.

\section{Acknowledgments}

Seungbeom Kim's work was supported by the Hongik University new faculty research support fund. Jinpyo Lee's work was supported by 2015 Hongik University Research Fund. Minjae Park's work was supported by 2015 Hongik University Research Fund. Minjae Park's research was also supported by Basic Science Research Program through the National Research Foundation of Korea funded by the Ministry of Education, Science and Technology (NRF2014R1A1A2053679). These research funds do not lead to any conflicts of interest regarding the publication of this manuscript.

\section{References}

[1] W. Elmaghraby and P. Keskinocak, "Dynamic pricing in the presence of inventory considerations: research overview, current 
practices, and future directions," Management Science, vol. 49, no. 10, pp. 1287-1309, 2003.

[2] X. Chen, M. Sim, D. Simchi-Levi, and P. Sun, "Risk aversion in inventory management," Operations Research, vol. 55, no. 5, pp. 828-842, 2007.

[3] D. Kahneman and A. Tversky, "Prospect theory: an analysis of decision under risk," Econometrica, vol. 47, no. 2, pp. 263-291, 1979.

[4] B. G. Hardie, E. J. Johnson, and P. S. Fader, "Modeling loss aversion and reference dependence effects on brand choice," Marketing Science, vol. 12, no. 4, pp. 378-394, 1993.

[5] N. C. Petruzzi and M. Dada, "Pricing and the newsvendor problem: a review with extensions," Operations Research, vol. 47, no. 2, pp. 183-194, 1999.

[6] A. Federgruen and A. Heching, "Combined pricing and inventory control under uncertainty," Operations Research, vol. 47, no. 3, pp. 454-475, 1999.

[7] A. Federgruen and A. Heching, "Multilocation combined pricing and inventory control," Manufacturing and Service Operations Management, vol. 4, no. 4, pp. 275-295, 2002.

[8] X. Chen and D. Simchi-Levi, "Coordinating inventory control and pricing strategies with random demand and fixed ordering cost: the infinite horizon case," Mathematics of Operations Research, vol. 29, no. 3, pp. 698-723, 2004.

[9] X. Chen and D. Simchi-Levi, "Coordinating inventory control and pricing strategies with random demand and fixed ordering cost: the finite horizon case," Operations Research, vol. 52, no. 6, pp. 887-896, 2004.

[10] M. E. Schweitzer and G. P. Cachon, "Decision bias in the newsvendor problem with a known demand distribution: experimental evidence," Management Science, vol. 46, no. 3, pp. 404-420, 2000.

[11] T.-H. Ho, N. Lim, and T. H. Cui, "Reference dependence in multilocation newsvendor models: a structural analysis," Management Science, vol. 56, no. 11, pp. 1891-1910, 2010.

[12] B. L. Fredrickson and D. Kahneman, "Duration neglect in retrospective evaluations of affective episodes," Journal of Personality and Social Psychology, vol. 65, no. 1, pp. 45-55, 1993.

[13] D. Kuksov and K. Wang, "The bright side of loss aversion in dynamic and competitive markets," Marketing Science, vol. 33, no. 5, pp. 693-711, 2014.

[14] J. Nasiry and I. Popescu, "Dynamic pricing with loss-averse consumers and peak-end anchoring," Operations Research, vol. 59, no. 6, pp. 1361-1368, 2011.

[15] J. Lee, "Inventory control by different service levels," Applied Mathematical Modelling, vol. 35, no. 1, pp. 497-505, 2011.

[16] J. Lee, "Dynamic pricing inventory control under fixed cost and lost sales," Applied Mathematical Modelling, vol. 38, no. 2, pp. 712-721, 2014.

[17] H.-S. Lau, "The newsboy problem under alternative optimization objectives," The Journal of the Operational Research Society, vol. 31, no. 6, pp. 525-535, 1980.

[18] L. Eeckhoudt, C. Gollier, and H. Schlesinger, "The risk-averse (and prudent) newsboy," Management Science, vol. 41, no. 5, pp. 786-794, 1995.

[19] M. Bouakiz and M. J. Sobel, "Inventory control with an exponential utility criterion," Operations Research, vol. 40, no. 3, pp. 603-608, 1992.

[20] V. Agrawal and S. Seshadri, "Impact of uncertainty and risk aversion on price and order quantity in the newsvendor problem," Manufacturing and Service Operations Management, vol. 2, no. 4, pp. 410-423, 2000.
[21] Y. Li, S. Sui, and S. Tong, "Adaptive fuzzy control design for stochastic nonlinear switched systems with arbitrary switchings and unmodeled dynamics," IEEE Transactions on Cybernetics, vol. 47, no. 2, pp. 403-414, 2017.

[22] Y. Li, S. Tong, and T. Li, "Observer-based adaptive fuzzy tracking control of MIMO stochastic nonlinear systems with unknown control directions and unknown dead zones," IEEE Transactions on Fuzzy Systems, vol. 23, no. 4, pp. 1228-1241, 2015.

[23] D. Simchi-Levi, X. Chen, J. Bramel et al., The Logic of Logistics. Theory, Algorithms, and Applications for Logistics and Supply Chain Management, Springer, 2005.

[24] X. Zhao, P. Shi, X. Zheng, and L. Zhang, "Adaptive tracking control for switched stochastic nonlinear systems with unknown actuator dead-zone," Automatica, vol. 60, pp. 193-200, 2015.

[25] R. Thaler, "Mental accounting and consumer choice," Marketing Science, vol. 4, no. 3, pp. 199-214, 1985.

[26] K. T. Talluri and G. J. Van Ryzin, The Theory and Practice of Revenue Management, vol. 68, Springer Science+Business Media LLC, Berlin, Germany, 2006.

[27] S. P. Anderson and A. de Palma, "Multiproduct firms: a nested logit approach," The Journal of Industrial Economics, vol. 40, no. 3, pp. 261-276, 1992.

[28] J. E. Smith, "Evaluating income streams: a decision analysis approach," Management Science, vol. 44, no. 12, pp. 1690-1708, 1998.

[29] Z.-J. M. Shen and X. Su, "Customer behavior modeling in revenue management and auctions: a review and New Research Opportunities," Production and Operations Management, vol. 16, no. 6, pp. 713-728, 2007.

[30] S. Kim, W. T. Huh, and S. Dasu, "Pre-announced posted pricing scheme: existence and uniqueness of equilibrium bidding strategy," Operations Research Letters, vol. 43, no. 2, pp. 151-160, 2015. 


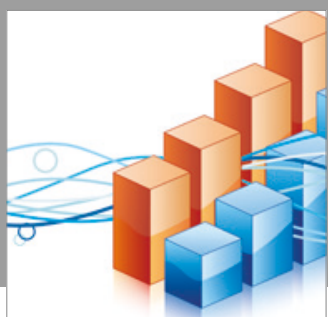

Advances in

Operations Research

vatersals

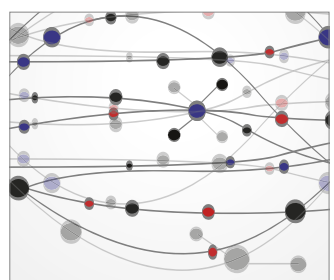

\section{The Scientific} World Journal
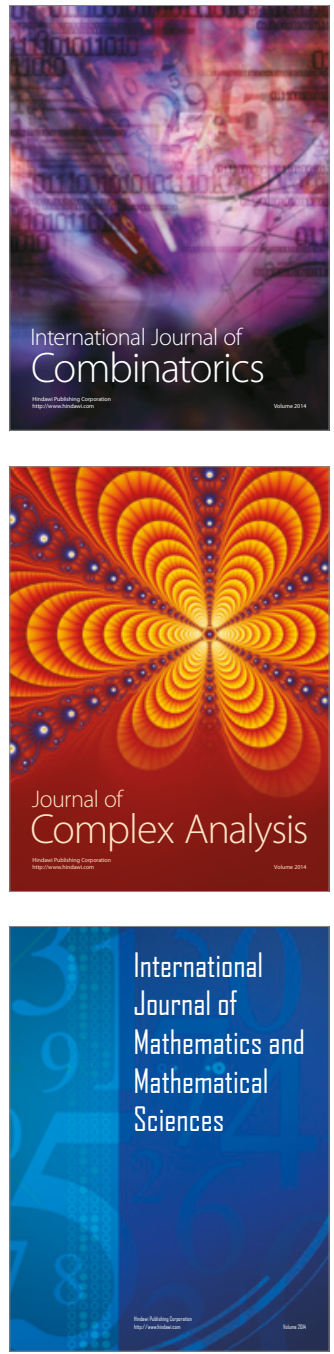
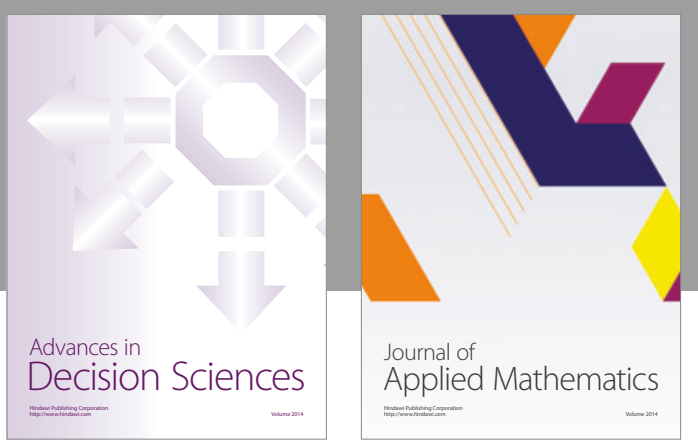

Algebra

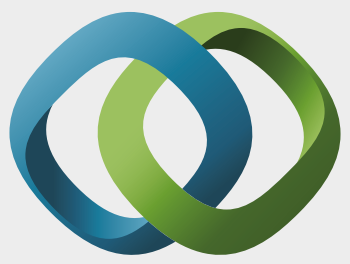

\section{Hindawi}

Submit your manuscripts at

https://www.hindawi.com
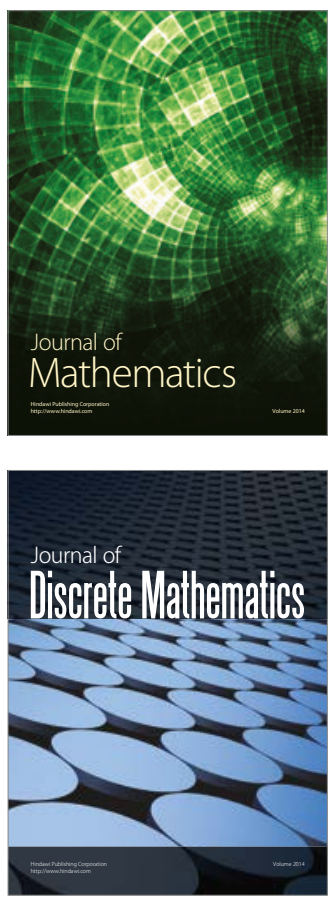

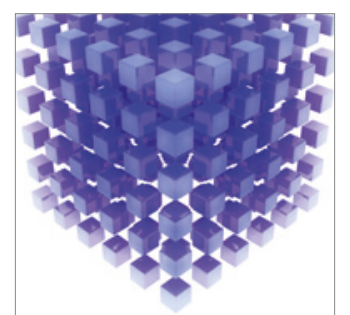

Mathematical Problems in Engineering
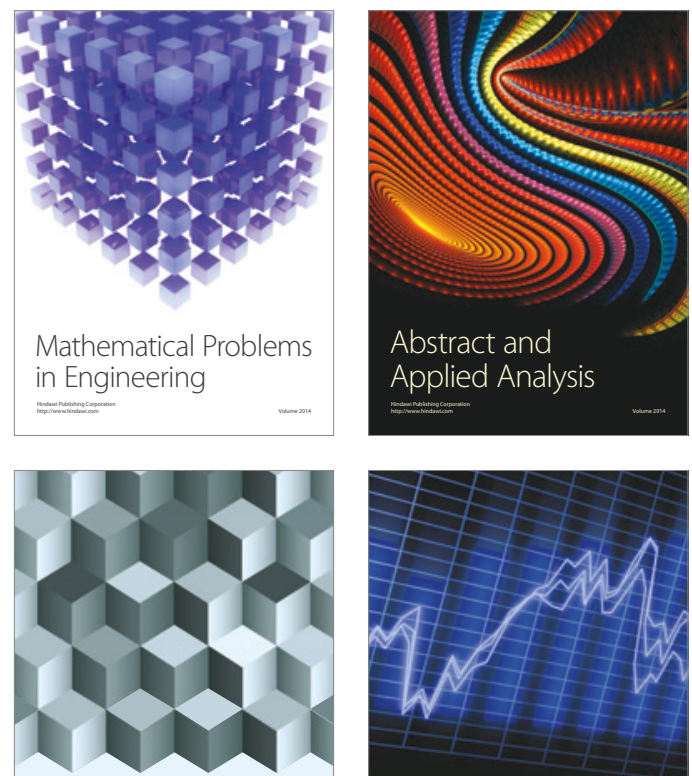

Journal of

Function Spaces

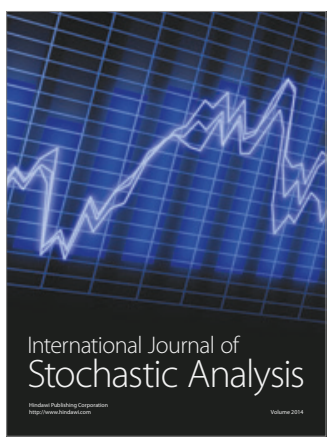

Probability and Statistics
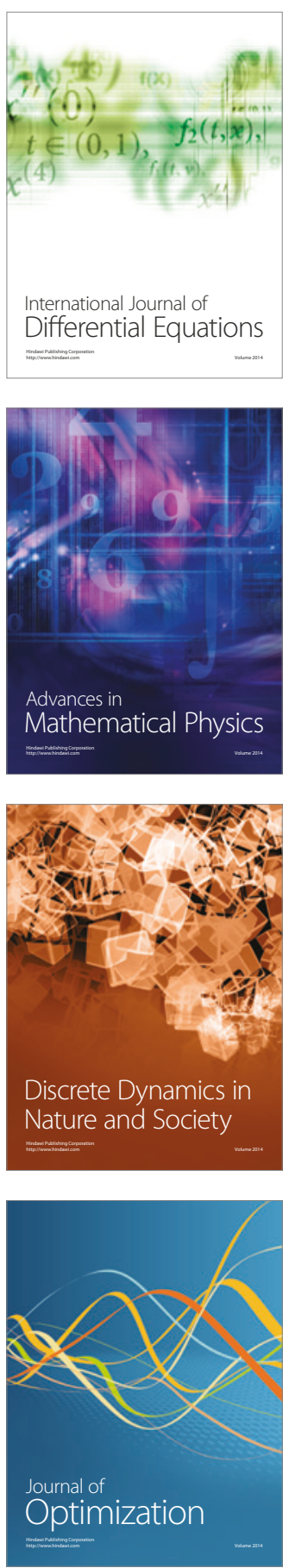